\title{
Induction of Fetal Rat Enterokinase (Enteropeptidase EC. 3.4.21.9) in Utero by Hydrocortisone and Actinomycin D
}

\author{
EMANUEL LEBENTHAL ${ }^{(3)}$ \\ Department of Medicine (Clinical Nutrition), The Children's Hospital Medical Center and Harvard Medical School, \\ Boston, Massachusetts, USA
}

\begin{abstract}
Summary
Enterokinase activity is first detected in the small intestine of the rat at the 20th day of gestation, whereas sucrase activity first appears in the 14th day of postnatal life. Intraperitoneal injection of hydrocortisone to pregnant rats before the normal appearance of enterokinase in fetuses causes the premature appearance of enterokinase ( $58 \pm 8$ units), but not of sucrase activity. The addition of actinomycin $D$ in the pregnant rat results in supermaximal stimulation of enterokinase activity $(229$ \pm 25 units). Sucrase activity is stimulated by hydrocortisone when given in the first 3 days of life (118 \pm 0.4 units). The maximal induction occurs 2 days before the normal appearance of the enzyme in untreated animals $(7.3 \pm 12$ units). The addition of actinomycin D diminished the effect of hydrocortisone on sucrase activity in the neonatal rat $(1.4 \pm 2$ units versus $1.8 \pm 0.4$ units in 3-day-old rats). Thus, enterokinase and sucrase of the small intestine of the fetal and infant rat respond differently to combined hydrocortisone and actinomycin $\mathbf{D}$. The response to hydrocortisone is age dependent and the maximal induction occurs before the time of the natural appearance of the enzymes. No effect is elicited after the normal appearance of enterokinase or sucrase.
\end{abstract}

\section{Speculation}

Glucocorticoids stimulate an early appearance of small intestinal enzymes only before the expected time of the natural developmental burst of activity. In both, sucrase and enterokinase, glucocorticoids have no effect after the enzymes are fully developed. New enzymes develop in clusters during the late fetal, neonatal, and late sucking periods. The effect of glucocorticoids on the "maturation" of the small intestine is limited to the induction of one phase only; i.e., only before the late fetal period is the precocious appearance of enterokinase possible. The induction of enterokinase activity can serve as an indicator for the early phase of maturation. Whereas the induction of sucrase activity can serve as a marker for late phase of maturation of the small intestine in the rat.

The superinduction of enterokinase, but not of sucrase activity, by the addition of actinomycin $D$ to glucocorticoids might be related to the difierent stability of the mRNA's of these enzymes.

The effects of hormones on specific enzymes in various systems, including intact animals, tissue explants, and cells in continuous culture have been studied extensively $(9,12,26)$.

During the third week of postnatal life in rats and mice structural (23), functional (11), and enzymatic (20) changes in the brush border surface of the small intestine occur, and the intestine approaches adult appearance and function.
The administration of glucocorticosteroids to infant mice and rats before these maturational changes causes a premature elongation of the microvilli (23) and increases in the activities of alkaline phosphatase (20), $\alpha$-glucosidases $(5,17,25)$, and leucylnaphthylamidase (21). In contrast, there is no effect of glucocorticosteroids on the small intestine of adult rats (4). The activities of the brush border-bound enzymes, sucrase and isomaltase, are undetected during the early suckling period $(5,17$, $25)$. Sucrase and isomaltase appear by the 15 th to 21 st postnatal day and attain adult values by the 30th postnatal day $(5,17,25)$. We studied the developmental pattern of enterokinase activity in the rat from fetal life to maturity and found that it is detected in the 20th day of gestation and achieves adult levels of activity around the time of birth.

In the present investigation we tried to elaborate the possibility of induction of the small intestinal enzymes in utero by injecting pregnant rats with glucocorticoids and actinomycin D. We used the determination of sucrase and enterokinase activities in the small intestine because of the different time of their appearance in the developing rat.

\section{MATERIALS AND METHODS}

In order to establish the normal appearance of enterokinase in utero in the small intestine, fetuses were removed from pregnant Riverside rats under ether anesthesia by cesarean section from the 14 th day of gestation until birth. In addition, 143 infant rats from birth to 25 days of age and 20 adult rats were killed at different ages to establish the normal values of the enzymes (Fig. 1). The small intestine of the fetuses from the pylorus to the cecum was removed and homogenized in 100 volumes distilled ice-cold water. A second group of pregnant rats at 15-18 days of gestation was injected daily for 3 days with hydrocortisone 50 $\mu \mathrm{g} / \mathrm{g}$, actinomycin D $0.25 \mu \mathrm{g} / \mathrm{g}$, and cyclohexamide $7 \mu \mathrm{g} / \mathrm{g}$, singly and in various combinations. The drugs were given in pharmacologic dosages. After 3 days of treatment, the fetuses were removed as cited previously. No pregnant rat survived 3 days of treatment with cyclohexamide and actinomycin $\mathrm{D}$ alone, or cyclohexamide together with hydrocortisone. Eleven of 12 pregnant rats that received cortisone alone survived; 8 of 35 pregnant rats that received hydrocortisone and actinomycin D survived. Sixty-five infant rats were injected daily for 3 days at different ages with hydrocortisone $50 \mu \mathrm{g} / \mathrm{g}$ and actinomycin D $0.25 \mu \mathrm{g} / \mathrm{g}$, and only 22 survived the treatment. Thirty-nine infant rats received hydrocortisone alone and 34 survived the treatment. In all animals enterokinase $(14,15)$, sucrase $(2)$, and protein (19) were determined in the mucosa of the small intestine.

Enterokinase has a very high specificity for trypsinogen and this physiologic substrate is, in fact, the only one known for the enzyme. This means that the determination of enterokinase 


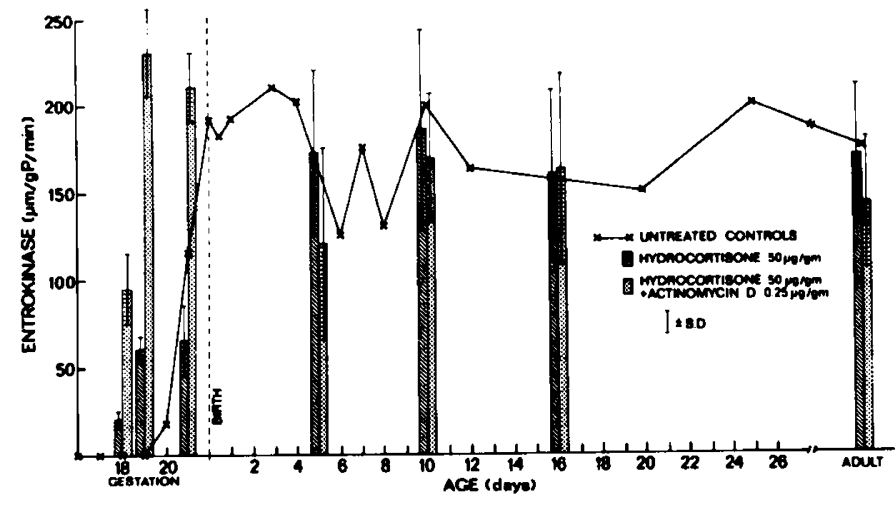

Fig. 1. The effect of hydrocortisone and actinomycin $D$ on intestinal enterokinase activity in intrauterine, perinatal, weaning, and adult rats. For the control animals each point represents the mean value of enterokinase activity that was determined from 6-20 animals. Hydrocortisone and actinomycin $\mathrm{D}$ were given for 3 days before the day of determination and each bar represents the mean \pm SD of 8-23 rats. Enterokinase activity is expressed as micromoles of benzoyl-DL-arginine $p$-nitroanilide- $\mathrm{HCl}$ hydrolyzed/g protein/min at $25^{\circ}$.

acitvity has to be performed in two steps as originally described by Kunitz (14). Trypsinogen was first incubated with the enterokinase-containing solution and then samples were removed from the activation mixture at suitable time intervals and analyzed for the amount of trypsin activity produced. In this method, Kunitz took into account the complications due to the action of trypsin formed, i.e., chiefly autocatalytic activation of trypsinogen itself by trypsin. This autocatalytic process is much reduced by using an extremely low trypsinogen concentration, and the transformation of inert protein is further suppressed by activation of $\mathrm{pH}$ 6.0.

Thus, the standard assay procedure for the determination of enterokinase activity described below is a micromodification of the method used by Hadorn et al. (10), which in turn was based on the method of Kunitz (14). The activation mixture $(20 \mu l 0.1$ $M$ sodium maleate buffer ( $\mathrm{pH} \mathrm{6.0),} 20 \mu$ l enterokinase-containing solution, and $240 \mu \mathrm{l}$ distilled water) was prepared and warmed to $25^{\circ}$, the incubation temperature. Incubation was started by the addition of $20 \mu$ l trypsinogen solution ( $2 \mathrm{mg}$ trypsinogen $/ \mathrm{ml} 0.005 \mathrm{~N} \mathrm{HCl}$ ). After a 30 -min activation the determination of the amount of trypsin formed was immediately started by the addition of an aliquot of the activation mixture to a tube with the reagents for the assay of trypsin activity (see above).

Different dilutions of each sample were analyzed to check the proportionality and to obtain an optimal reading value. A blank tube was run (with omission of trypsinogen). This tube also revealed any trypsin accidentally present in the enzyme sample and accounted for autocatalysis by trypsin. In separate tubes, it was determined that the trypsinogen itself was free of trypsin and that no autoactivation of the trypsinogen occurred during the experimental procedure. Analysis of samples from an enterokinase stock solution (a pooled homogenate stored at $-20^{\circ}$ ) was further used to check the reliability of the assay system. For the trypsin determination the substrate used was benzoyl-DL-arginine $p$-nitroanilide- $\mathrm{HCl}$ dissolved in a small volume of dimethylsulfoxide and then diluted with $0.05 \mathrm{M}$ Tris buffer ( $\mathrm{pH} \mathrm{8.2)}$ containing $0.02 \mathrm{M} \mathrm{CaCl}_{2}$ to give a substrate concentration of $0.001 \mathrm{M}$. Incubation at $25^{\circ}$ was started by the addition of 300 $\mu$ activation mixture (see above) to $1.5 \mathrm{ml}$ substrate buffer solution and stopped after $30 \mathrm{~min}$ by the addition of $300 \mu \mathrm{l} 30 \%$ (v/v) acetic acid. The color was read in a Beckman DU spectrophotometer at $409 \mathrm{~nm}$. A standard curve with different amounts of $p$-nitroaniline was made for the calculation of the enterokinase activity. A unit of trypsin is the activity that hy- drolyzes $1 \mu \mathrm{mol}$ benzoyl-DL-arginine $p$-nitroaniline- $\mathrm{HCl}$ in 1 min. One unit of enterokinase is the activity that activates 1 unit trypsin in $1 \mathrm{~min}$.

\section{RESULTS}

Enterokinase activity first appeared in the untreated small intestine of the fetal rat at the 20th day of gestation (Fig. 1) and within 24-48 hr approximated adult levels. In contrast, the activity of sucrase appeared on the 14th day of postnatal life and attained adult levels 6-9 days later (Fig. 2). Pregnant rats injected with hydrocortisone on the 15 th day for 3 days showed enterokinase activity in the fetuses on the 18th day of gestation. When hydrocrotisone was given on the 16 th day an even greater response occurred. Sucrase activity, however, is not stimulated in the fetus by hydrocortisone injection in the pregnant mother. The addition of actinomycin $D$ to hydrocortisone for 3 days produced a synergistic effect evidenced by an amplification in the premature activity of enterokinase. Rats similarly treated starting 1 day later showed levels of activity that are found in adults (Fig. 1). The closer the time to the normal appearance of enterokinase activity, the greater was the induction of enzyme. No effect of hydrocortisone or hydrocortisone plus actinomycin $\mathrm{D}$ was noted after the regular appearance of enterokinase activity (Fig. 1).

The administration of hydrocortisone to infant rats in the first day of life for 3 days caused premature appearance of sucrase activity on the third day (Fig. 2). The closer the suckling rat is to 14 or 15 days of age (the time of normal appearance of sucrase activity), the higher the levels of the premature activity of sucrase (Fig. 2). Injection of hydrocortisone on the 12th day of life for 3 days caused the highest possible induction of sucrase activity, $7.3 \pm 1.2$ units on the 15 th day (Fig. 2). The administration of hydrocortisone and actinomycin $D$ to infant rats caused a diminished induction of sucrase activity as compared with hydrocortisone alone (Fig. 2). Hydrocortisone administered from the third day of postnatal life for 3 days caused an induction of sucrase activity which peaked at the seventh day and declined thereafter. Induction produced by injection of hydrocortisone from the 10th day to 13 th day caused a lasting peak of sucrase activity from the 14th day, equivalent to full adult activity. Thus, only after the 10 th day will the administration of hydrocortisone produce a permanent induction which approaches the full scale of adult sucrase activity. The addition of actinomycin $D$ to hydrocortisone diminished the effect on the premature activity of sucrase, although it caused a synergistic effect on the premature appearance of enterokinase activity.

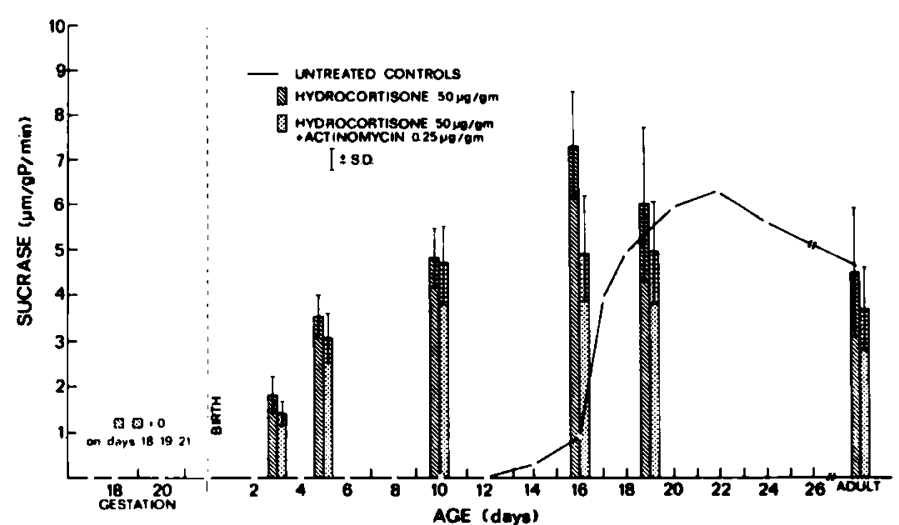

Fig. 2. The effect of hydrocortisone and actinomycin D on intestinal sucrase activity in intrauterine, perinatal, weaning, and adult rats. For the control animals each point represents the mean value of 6-20 animals. Hydrocortisone and actinomycin $D$ were given for 3 days before the day of determination and each bar represents the mean \pm SD of 5-9 rats. Sucrase activity is expressed as micromoles of sucrose hydrolyzed/g protein $/ \mathrm{min}$ at $37^{\circ}$. 


\section{DISCUSSION}

The major finding of these experiments reveals that intraperitoneal injection of hydrocortisone to pregnant rats before the normal appearance of enterokinase precipitates in utero a premature activity of enterokinase. In the developing rat new enzymes appear in clusters during the late fetal, neonatal, and late suckling periods. There is ample evidence that enzymes of late suckling period rise in response to adrenocortical stimulation $(5$, $9,11,12,17,20,21,23,25,26)$. To our knowledge, the stimulation of rat intestinal enzymes in the late fetal period has not been studied previously. However, data is available on the induction of pulmonary maturation in the late fetal period $(1,7$, 13).

The administration of glucocorticosteroids to rabbit fetuses showed evidence of increased pulmonary maturation, as shown by surface tension properties of lung extracts (13). In the fetal lung corticosteroids induced lecithin synthesis and increased the activity of choline phosphotransferase (7). These results are consistent with the proposal that corticosteroids lead to earlier development of alveolar surface active phospholipid. Buckingham et al. (1) suggested that the lung, as a derivative of the same embryonic tissue as the intestine, might have the same response to glucocorticoids. Enterokinase appears in the late fetal period, whereas sucrase activity in the late suckling period of the rat. It is conceivable from our data that glucocorticoids given in the late gestational period can not induce the appearance of an enzyme, such as sucrase, that appears in the late suckling period. Both enterokinase and sucrase are located in the small intestine but there is a difference in their cellular localization $(3,16)$. It is well established that sucrase is a brush border membrane-bound enzyme (3) localized in the mature epithelial cell of the small intestine. As to the topographic and cellular localization of enterokinase, conflicting data exist. One group proposed that the duodenum and Brunner's glands are involved in the formation of enterokinase (6). Another group have demonstrated that enterokinase is present along the entire small intestine and exclusively in the villous epithelial cells (22). On the subcellular level, the enzyme appears to be bound to the brush border membrane of these cells (22). Another group has shown that enterokinase in the pig is synthetized exclusively by the duodenal mucosa (18) and in addition, that high levels of the free enzyme are encountered in ileal content (18). Still a fourth group, using a fluorescent antibody technique, revealed that porcine enterokinase is concentrated in the goblet cell and is localized diffusely on the surface of the intestinal epithelium (27). Recently, we found that enterokinase in the rat intestine is mainly in a free form, localized in the soluble and mucin fraction (16). The different localizations of enterokinase and sucrase in the small intestine can explain the appearance of enterokinase in late fetal life, in contrast to sucrase activity that appears in the late suckling period. It is possible that glucocorticoids are inducing enterokinase and the maturity of the mucin fraction before the late fetal period. The high mortality rate observed in the pregnant rats and the fetuses receiving actinomycin $\mathrm{D}$ and cyclohexamide may be due to an altered response to these pharmacologic doses of these drugs during pregnancy.

The phenomenon whereby the inclusion of actinomycin D after corticosteroid treatment causes an exaggerated accumulation of enzyme has been called superinduction (8). One group (24) explains that the decrease in rate of degradation of the enzyme is greater than the decrease in rate of synthesis, hence an accumulation of enzyme. Another group (28) suggests that the mRNA is synthesized continually and that it can interact with ribosomes to direct the synthesis of enzyme or it can interact reversibly with a repressor. The repressor is postulated to have a rapid turnover. Therefore, an inhibition of its synthesis by actinomycin D will result in a decreased concentration of the repressor and lead to more mRNA available for translation. Still another group (18) postulates that the increase in absolute rate of protein synthesis results from the fact that peptide chain elongation is rate limiting. When some unstable mRNA's are lost, the remaining (stable) mRNA's are read more rapidly.

A similar superinduction by corticosteroids and actinomycin D was observed with choline incorporation and induction of choline phosphotransferase in the fetal lung (7). It was postulated that steroids can be useful in the treatment of respiratory distress syndrome in premature human infants (13). The ability of the rat fetal small intestinal enterokinase activity to respond in utero to administration of hydrocortisone to pregnant rats illustrates the possible role of steroids in causing earlier development of rat gut. It is dangerous to extrapolate to the role of steroids on the maturation of human fetal gut. However, with increasing success in treatment of pulmonary complications in the premature infant, the question of nutrition becomes a more important issue in survival. The possible early maturation of rat small intestine by corticosteroids makes it prudent to further investigate these results as a new modality for treatment, especially in relation to induction of the intestinal function that appears in late fetal life.

\section{CONCLUSION}

Enterokinase activity appeared on the 20th day of gestation of fetal rats and, within 24-48 hr, achieved adult levels. Pregnant rats injected with hydrocortisone on the 15 th day for 3 days showed enterokinase activity in the fetuses on the 18th day of gestation. The addition of actinomycin $\mathrm{D}$ to hydrocortisone for 3 days produced a synergistic effect by amplification in the premature activity of enterokinase. Injection of hydrocortisone on the 12 th day of life for 3 days caused the highest possible induction of sucrase activity. The addition of actinomycin $D$ to hydrocortisone diminished the induction of sucrase activity as compared with hydrocortisone alone. Sucrase activity is not stimulated in the fetus by hydrocortisone injection in the pregnant mother. No effect of hydrocortisone occurred after the regular appearance of the enzymes.

\section{REFERENCES AND NOTES}

1. Buckingham, S., McNary, W. F., Sommers, S. C., and Rothschild, J.: Is lung an analog of Moog's developing intestine? I. Phosphatases and pulmonary alveolar differentiation in fetal rabbits. Fed. Proc., 27: 328 (1968).

2. Dahlqvist, A.: Method of assay of intestinal disaccharidases. Anal. Chem., 7: 18 (1964).

3. Dahlqvist, A. and Nordstrom, C.: The distribution of disaccharidase activities in the villi and crypts of the small intestinal mucosa. Biochim. Biophys. Acta, 113: 624 (1966).

4. Deren, J. J., Broitman, S. A., and Zamchock, N.: Effect of diet upon intestinal disaccharidases and disaccharide absorption. J. Clin. Invest., 46: 186 (1967).

5. Doell, R. G., and Kretchmer, N.: Intestinal invertase: Precocious development of activity after injection of hydrocortisone. Science, 143: 42 (1964).

6. Eggermont, E., Molla, A., Tytgat, G., and Rutgeerts, L.: Distribution of enterokinase activity in the human intestine. Acta Gastroenterol. Belg., 34: 655 (1971).

7. Farrell, P. M., and Zachman, R. D.: Induction of choline phosphotransferase and lecithin synthesis in the fetal lung by corticoids. Science, 179: 297 (1973).

8. Garren, L. D., Howell, R. R., Tomkins, G. M., and Crocco, R. M.: A paradoxical effect of Actinomycin D: The mechanism of regulation of enzyme synthesis by hydrocortisone. Proc. Nat. Acad. Sci. U. S. A., 52: 1121 (1964)

9. Greengard, O.: Enzymatic differentiation in mammalian liver. Science, 163: 891 (1969).

10. Hadorn, B., Tarlow, M. J., Lloyd, J. K., and Wolff, O. H.: Intestinal enterokinase deficiency. Lancet, $1: 812$ (1969).

11. Halliday, R. L.: The effect of steroid hormones on the absorption of antibody of the young rat. J. Endocrinol., 18: 56 (1959).

12. Knox, W. E., and Greengard, O.: The regulation of some enzymes of nitrogen metabolism - An introduction to enzyme physiology. Advan. Enzyme Regul., 3: 247 (1965).

13. Kotas, R. V., and Avery, M. E.: Accelerated appearance of pulmonary surfactant in the fetal rabbit. J. Appl. Physiol., 30: 358 (1971).

14. Kunitz, M.: Formation of trypsin from crystalline trypsinogen by means of enterokinase. J. Gen. Physiol., 22: 429 (1939).

15. Lebenthal, E., Antonowicz, I., and Shwachman, H.: Enterokinase and trypsin activities in pancreatic insufficiency and diseases of the small intestine. Gastroenterology, 70: 508 (1976)

16. Lebenthal, E., and Morrissey, G. W.: Subcellular localization of enterokinase (Enteropeptidase EC 3.4.4.8) in rat small intestine. Gastroenterology, 70: 
48 (1976).

17. Lebenthal, E., Sunshine, P., and Kretchmer, N.: Effect of carbohydrate and corticosteroids on activity of $\alpha$-glucosidases in intestine of the infant rat. J. Clin. Invest., 51: 1244 (1972).

18. Louvard, S., Maroux, J., Baratti, J., and Desnuelle, P.: On the distribution of enterokinase in porcine intestine and on its subcellular localization. Biochim. Biophys. Acta, 309: 127 (1973).

19. Lowry, O. H., Rosebrough. N. J., Farr, A. L., and Randall, R. J.: Protein measurement with the Folin phenol reagent. J. Biol. Chem., 193: 265 (1951).

20. Moog, F.: The functional differentiation of the small intestine. III. The influence of the pituitary-adrenal system on the differentiation of phosphatase in the duodenum of the suckling mouse. J. Exp. Zool., 124: 329 (1953).

21. Moog, F., Birkenmeier, E. H., and Glazier, H. S.: Leucylnaphthylamidase activity in the small intestine of the mouse: Normal development and influence of cortisone and antibiotics. Develop. Biol., 25: 398 (1971).

22. Nordstrom, C., and Dahlqvist, A.: The cellular localization of enterokinase. Biochim. Biophys. Acta, 198: 621 (1970)

23. Overton, J.: Fine structure of the free surface in developing mouse intestinal mucosa. J. Exp. Zool, 159: 195 (1965).

24. Reel, J. R., and Kenney, F. T.: "Superinduction" of tyrosine transaminase in hepatoma cell culture: Differential inhibition of synthesis and turnover by Actinomycin D. Proc. Nat. Acad. Sci U. S. A., 61: 200 (1968).

25. Rubino, A., Zimbalatti, F., and Auricchio, S.: Intestinal disaccharidase activities in adult and suckling rats. Biochim. Biophys. Acta, 92: 305 (1964).

26. Schimke, R. T., and Doyle, D.: Control of enzyme levels in animal tissues. Ann. Rev. Biochem., 39: 929 (1970).

27. Takano, K., Suzuki, T., and Yasuda, K.: Immunohistochemical localization of enterokinase in the porcine intestine. Okajimas Folin Anat. Jap., 48: 15 (1971).

28. Tomkins, G. M., and Gelehrter, T. D.: The present status of genetic regulation by hormones. In: G. Litwak: Biochemical Actions of Hormones, Vol. II, pp. 1-20 (Academic Press, New York, 1972).

29. I am indebted to Gregory Morrissey, M.S., for his skillful technical assistance, Harry Shwachman for his support and encouragement, and Olga Greengard, the Department of Biological Chemistry at Harvard Medical School, for her criticism, suggestions, and review of the article.

30. This research was supported by the Cystic Fibrosis Foundation, Ina Sue Perlmutter Fund, Illman Foundation, and Hearst Foundation.

31. Requests for reprints should be addressed to: Chief, Division of Gastroenterology, Children's Hospital, 219 Bryant St., Buffalo, N. Y. 14222 (USA).

32. Received for publication June $21,1976$.

33. Accepted for publication September 22, 1976
Alternative pathway properdin

$\mathrm{C} 3, \mathrm{C} 3 \mathrm{~b}$ complement inulin serum

sickle cell disease

total hemolytic activity (CH50)

\title{
Alternative Pathway of Complement in Sickle Cell Disease
}

\author{
RONALD G. STRAUSS, ${ }^{(26)}$ THERESA ASBROCK, JUDITH FORRISTAL, AND CLARK D. WEST \\ Department of Pediatrics, The University of Cincinnati College of Medicine and the Comprehensive Center for \\ Sickle Cell Disease, Children's Hospital Medical Center, Cincinnati, Ohio, USA
}

\section{Summary}

Thirty-one patients, 10 months to 20 years of age, were studied. A complement abnormality was not identified in sera from patients with sickle cell disease (SCD) by the methods employed in the present study. Concentrations of C3, factor B, total hemolytic activity (CH50), properdin, and C3b inactivator were similar in sera from patients and control subjects (Table 1 and Fig. 2). Although concentrations of C3b inactivator protein were below normal in a few patients, there was no evidence that these levels were low enough to alter the functions mediated by this protein.

Initiation of the complement sequence via the alternative pathway by reaction with inulin was equal in patient and control sera when assessed by the activation of factor $B$, cleavage of $C 3$, and the consumption of hemolytic complement components ( $\mathrm{Ta}$ ble 1). Lysis of erythrocytes treated with reduced glutathione was similar in patient and control sera during alternative pathway activation (Fig. 3), indicating comparable formation of lytic complexes via this pathway.

An abnormality of the alternative pathway was not detected when the serum from patients with sickle cell disease was reacted with inulin. Thus, this polysaccharide, although commonly employed to assess alternative pathway function, is not satisfactory for studying serum from these patients. In addition, activation of the alternative pathway by cobra venom factor was comparable with controls when assessed by the lysis of glutathione-treated erythrocytes.

\section{Speculation}

Defective function of the alternative pathway of complement activation has been described in the serum of patients with sickle cell anemia. The precise abnormality may be revealed by a quantitative and functional assessment of the components of this pathway.

Fulminant bacterial infections, particularly with Streptococcus pneumoniae, occur with increased frequency in children with $\operatorname{SCD}(1,20)$, and several abnormalities of the body defense mechanisms have been reported to account for the propensity to infections in this disorder (7). Defects related to the opsonization, phagocytosis, and killing of bacteria are most important because these defenses are required to control pyogenic infections. An abnormality of pneumococcal opsonization in serum from patients with SCD has been attributed to the heat-labile opsonin system (23). The precise serum defect is as yet unidentified, but evidence suggests that it involves the alternative pathway of complement (8). In this report a quantitative and functional assessment was made of this pathway and related proteins 